\title{
Minute Times Femtogram per Milliliter
}

National Cancer Institute

\section{Source}

National Cancer Institute. Minute Times Femtogram per Milliliter. NCI Thesaurus. Code C85724.

Minutes times femtograms per milliliter. 